\title{
The Course of Well-Being in Romantic Relationships: Predicting Positive Affect in Dating Participants
}

\author{
Katherine Jacobs Bao \\ Psychology Department, University of California, Riverside, USA \\ Email: katherine.bao@email.ucr.edu
}

Received August $11^{\text {th }}, 2012$; revised September $8^{\text {th }}, 2012$; accepted October $11^{\text {th }}, 2012$

\begin{abstract}
People use different methods to make themselves happier, but their attempts at lasting happiness are often thwarted by the hedonic adaptation process. We examined changes in well-being over 8 weeks in participants who were involved in romantic relationships and those who were not. On average, both groups declined in well-being over time, but the relationship group experienced more positive emotions overall. High positive affect was predicted by higher aspirations, higher passionate love, and being in a same-ethnicity relationship. None of the variables we measured significantly predicted changes in positive affect over time, which may be due to the short duration of the study.
\end{abstract}

Keywords: Happiness; Well-Being; Hedonic Adaptation; Romantic Relationships

\section{Introduction}

"The greatest degree of inner tranquility comes from the development of love and compassion. The more we care for the happiness of others, the greater is our own sense of well-being."

-Tenzin Gyatso, the 14th Dalai Lama

What makes people happier? Is it buying the latest gadget? Trying a new hobby? Starting a new relationship? A variety of activities allow people to experience increases in happiness, but it is unclear whether such increases are long-lasting. Consistent with researchers' definitions, we conceptualize happiness (also known as subjective well-being) as a combination of high life satisfaction, frequent positive affect, and infrequent negative affect, (e.g., Diener, Suh, Lucas, \& Smith, 1999). Both empirical and anecdotal evidence suggest that most attempts by individuals to increase their happiness result in a temporary boost in well-being, followed by a gradual return to their original "baseline" level. By understanding the processes and mechanisms underlying this return to baseline (aka "adaptation"), researchers may advance understanding of how people can learn to slow the process down or arrest it entirely, thereby maintaining their initial happiness boost.

\section{Hedonic Adaptation}

Hedonic adaptation is reflected by a change (gain or loss) in happiness after the experience of a valenced stimulus or event, followed by a gradual return to baseline (Frederick \& Loewenstein, 1999). Frederick and Loewenstein (1999) have argued that hedonic adaptation is evolutionarily adaptive. When individuals experience high levels of positive or negative affect, they cannot help but focus on those intense feelings. This attention on their affect can make it difficult to function, because people need to focus on their basic needs in order to survive. Thus, people hedonically adapt as a means of reducing high arousal, allowing them to direct their attention to more important needs, as well as to novel opportunities and threats. Finally, if individuals did not adapt to the attainment of their goals, they would be less likely to aspire to and pursue even loftier and more significant goals.

To explore the process of adaptation, several researchers have investigated changes in people's life satisfaction both before and after a major life event, using longitudinal designs. Several large nationally representative panel studies have found evidence of a failure to adapt to negative events. In these studies, participants were followed for several years before and after a negative event, such as a major disability (Lucas, 2007), unemployment (Lucas, Clark, Georgellis, \& Diener, 2004), divorce (Lucas, 2005), widowhood (Lucas, Clark, Georgellis, \& Diener, 2003; Lucas \& Clark, 2006). On average, participants would begin to approach, but never reach, their baseline levels of well-being after the negative event. Perhaps people would eventually fully recover if followed for longer periods of time, but it is possible that, on average, people never recover after certain events. At the very least, these studies tell us that adaptation to negative life events is a slow process.

Although fewer studies have been conducted on people's reactions to positive events, interestingly, these studies show different rates of adaptation in response to positive versus negative experiences. For example, Lucas and colleagues observed changes in life satisfaction in the years before and after marriage and found that although participants varied in their degree of adaptation, on average, people tended to return to baseline levels of life satisfaction after about 2 years (Lucas et al., 2003). Similarly, in the work domain, researchers have followed people starting a new job and found that, on average, people quickly lost the "boost" in well-being from starting the job and returned to baseline levels (Boswell, Boudreau, \& Tichy, 2005). The results of these studies support the idea that adaptation to positive events is faster and more complete than adaptation to negative events.

In sum, the literature suggests that hedonic adaptation to positive experiences may be one of the biggest obstacles to happiness. After all, if people ultimately "get used to" everything positive that happens in their lives, then how can they 
ever become happier? The implication is that an individual who desires to increase his or her happiness would do well to put effort into thwarting adaptation. Those who experience a positive life event (such as starting a new relationship) may be able to use certain strategies to either slow or stop adaptation. The hedonic adaptation prevention model (Lyubomirsky, 2011; Sheldon \& Lyubomirsky, 2012) posits that adaptation occurs via two paths - through decreases in positive emotions and through increases in aspirations. According to the model, when someone experiences a positive change, such as beginning a new romantic relationship, that change will generate a stream of positive events, which, in turn, will trigger increases in positive emotions. These increases in positive emotions lead to a boost in well-being. However, over time, the positive life change will produce fewer and fewer positive events, and thus fewer positive emotions, so well-being will begin to decline. In this case, positive events and positive emotions are mediators of the adaptation process. After all, more positive events and positive emotions are associated with higher well-being. For example, as a young man begins a new relationship, he experiences new positive events (e.g., going out on fun dates and meeting new people) and thus more positive emotions (e.g., excitement, energy, affection). This leads to a boost in happiness. However, over time, these positive events and positive emotions become less frequent, so he experiences fewer and smaller boosts in happiness, and thus begins to adapt.

Another path that underlies the process of adaptation involves a rise in people's aspiration levels, which typically occurs after they experience a positive change and the subsequent increase in positive events. In other words, over time, the positive events begin to become expected and predictable, and thus do not lift their well-being as much as they used to. Aspirations are another mediator of adaptation, such that higher aspirations are associated with lower well-being. For example, after a college student in a new relationship starts going out on dates every Friday night, she starts to expect to go out on those dates each week, and thus each date leads to less of a gain in wellbeing than the previous one. She may even start to develop higher aspirations (e.g., going out on more fun dates every week or boosting her partner's level of commitment), so the once-a-week date does not provide as much of a boost in wellbeing as it once did.

According to the hedonic adaptation prevention model, both paths underlying the course of hedonic adaptation are also moderated by several key variables, including surprise, variability, and appreciation (Lyubomirsky, 2011; Sheldon \& Lyubomirsky, 2012). The more surprising and varied the positive events, the longer it takes to adapt to them. So a couple that engages in a different activity each time they have a date will adapt to dating less quickly than a couple that does the same activity each date night. For example, Aron and colleagues used both survey and experimental methods to examine the association between shared exciting activities and relationship satisfaction (Aron, Norman, Aron, McKenna, \& Heyman, 2000). The researchers found that couples that participated in novel and arousing activities had higher relationship satisfaction than those who participated in more mundane activities. Furthermore, using an experimental design, they found that induced shared participation in novel and arousing activities increased relationship quality, compared to performing a neutral task. In another longitudinal study, researchers also found that self-reported marital boredom predicted significantly lower rela- tionship satisfaction 9 years later, even after controlling for relationship satisfaction at the initial assessment (Tsapelas, Aron, \& Orbuch, 2009). Novelty and excitement are related to variety and surprise, two moderators of the adaptation process. Thus, couples that participate in more novel and exciting activities may adapt more slowly over time than those who do not participate in such activities, because these experiences are more variable and surprising.

Also, the less one appreciates one's positive change in circumstances, whether the change is a new relationship, a new car, or a new job, the more quickly one adapts. Appreciation may slow adaptation by guarding against social comparisons and increasing expectations (Layard, 2005). For example, if an individual comes to expect a romantic outing each Friday and begins to take it for granted, then she may not appreciate the time spent together or the relationship in general as much, and thus the outing produces less of a boost in well-being. Striving to increase one's appreciation of positive changes, as well as the other moderators discussed, may be critical to learning how to forestall adaptation.

\section{Romantic Relationships}

Relatively little research has been conducted on adaptation to romantic relationships, but the large existing literature on other aspects of romantic relationships bears some relevance for how adaptation may play out in relationships and how it may be thwarted. Many studies, for example, have found evidence for decreases in satisfaction across the course of both marital and dating relationships (Kurdek, 1999, 2002; Rusbult, 1983; see Karney \& Bradbury, 1995, for a review). These patterns of results are consistent with the phenomenon of hedonic adaptation. However, such studies typically do not follow participants before and after starting a relationship; they examine participants who are already in romantic relationships.

In the present study, we charted changes in well-being for people who were in romantic relationships (i.e., the "relationship group") and those who were not in romantic relationships (i.e., the "control group") using online surveys that were completed once a week for 8 weeks.

\section{Hypotheses}

- The relationship group will have higher well-being than the control group. Research suggests that people in relationships tend to be happier than those who are not in relationships (Dush \& Amato, 2005; see Lyubomirsky, King, \& Diener, 2005, for a review).

- All participants will show a decline in well-being over time. Previous studies have found that students' well-being tends to decrease over the course of an academic quarter (Lyubomirsky, Sheldon et al., 2005).

- The length of the relationship will predict well-being, such that longer relationships will be associated with lower wellbeing, and shorter relationships will be associated with a steeper decline in well-being over time. People in longerterm relationships (i.e., 2 or more years) will likely have already adapted, and thus experience lower well-being. Those in newer relationships will still be experiencing adaptation, which may be associated with more rapid declines in wellbeing.

- Individual differences in relationship composition will be 
associated with different rates of adaptation. Specifically, first, participants in same-sex relationships will decline in well-being more slowly than those in opposite-sex relationships. Second, participants in different-ethnicity relationships will decline in well-being more slowly than those in same-ethnicity relationships. Participants in same-sex or different-ethnicity relationships may face disapproval from their family (Kurdek, 2004) or society (Donovan, Heaphy, \& Weeks, 1999; Murstein, Murigihi, \& Malloy, 1989). These outside threats to the relationship may increase the elements of variety and surprise experienced on a daily basis, thus slowing the rate of adaptation (Lyubomirsky, 2011).

- Higher aspirations will predict a more rapid decline in well-being over time. As discussed above, Lyubomirsky's model of adaptation to positive events (2011) posits that aspirations mediate the adaptation process, such that higher aspirations increase the rate of adaptation.

- Higher passionate love scores will be associated with higher levels of well-being overall and a slower decline in well-being. Previous research has found passionate love to be a significant predictor of positive emotions (Kim \& Hatfield, 2004). Participants who are experiencing high levels of passionate love are relatively more likely to be in the early stages of their relationship or to have reignited intense feelings and/or intimacy in their relationship, and therefore are less likely to have adapted. High levels of passionate love may also buffer against adaptation, because passion may be associated with higher levels of surprise and variety within a relationship.

\section{Method}

\section{Participants}

Three-hundred five undergraduate students (77 men, 210 women) at a Southern California public university participated in the study. Participants were recruited from introductory Psychology courses, and received course credit for their participation. Students ranged in age from 18 to $34(\mathrm{M}=19.25)$, and the ethnicities of the sample reflected that of the university (33.8\% Asian, 22.6\% Latino, 17.7\% White, 2.6\% African American, 9.2\% biracial, $8.2 \%$ other, and 5.9\% unknown). The "control" group comprised 155 students who had not been in a romantic relationship for at least the last 3 months. In addition, 150 students were recruited for the "relationship" group - that is, those students who had been in a romantic relationship for a minimum 1-month duration. Of the participants in the relationship group, $77 \%$ had an opposite-sex partner, $17.6 \%$ were males with male partners, and 5.4\% were females with female partners. In the relationship group, $65.5 \%$ of participants were the same ethnicity as their partner, and $34.5 \%$ were a different ethnicity than their partner.

\section{Procedure}

We followed participants over the course of 8 weeks (identified as Week 1 through Week 8). Students in both the relationship and control groups completed online questionnaires assessing their well-being, as well as other variables, once a week. The relationship group completed additional measures about their romantic relationships each week.

During Week 1, we first measured basic demographic in- formation. Additional measures were administered each week of the study. Participants were asked about their current wellbeing, followed by measures of aspirations about future affect and relationship satisfaction (or life satisfaction) for the next week, followed by a measure of emotion. Relationship group participants also completed a measure of passionate love after the emotions measure.

\section{Materials}

Demographics. We collected information about the participants' sex, ethnicity, and religious affiliation. Similar information was also obtained about the participant's partner for those in the relationship group.

Current well-being. We measured participants' current wellbeing each week using an affect measure and a satisfaction measure, which differed slightly for our two groups. All participants used a sliding scale, which ranged from extremely negative to extremely positive for the affect questions and extremely dissatisfied to extremely satisfied for the satisfaction questions. The slider recorded scores from 0 to 600 , but the participants could not see these numbers. For the control participants, we measured general affect ("How do you feel right now?") and life satisfaction ("How satisfied with your life are you right now?"). For the relationship participants, we measured feelings about the relationship ("How do you feel about your relationship right now?") and relationship satisfaction ("How satisfied with your relationship are you right now?"). Reliability for the control group items was higher (Cronbach's $\alpha$ from 0.80 to 0.93 ) than for the relationship group items (Cronbach's $\alpha$ from 0.67 to 0.82 ).

Current aspirations. We measured participants' aspirations each week using an affect measure and a satisfaction measure. This measure mirrored the well-being measure, above. We asked about future affect ("How do you expect to feel this week?/How do you expect to feel this week about your relationship partner?") and future satisfaction ("How satisfied with your life do you expect to feel this week?/How satisfied with your relationship do you expect to feel this week?") of the control and relationship groups, respectively. Similar to the wellbeing measure, reliability for the control group questions was higher than that for the relationship group questions (Cronbach's $\alpha$ from 0.84 to 0.94 and from 0.61 to 0.88 , respectively).

Multiple Affect Adjective Check List (MAACL). We measured emotions using the MAACL (Zuckerman \& Lubin, 1965), but abridged the measure from 70 to 55 items by removing items that had not shown much variance in previous studies in our laboratory. The MAACL items are yes/no questions about whether participants felt a particular emotion (e.g., affectionate, hostile, joyful, discouraged) this week. We also added questions about the frequency and intensity of emotions for each emotion the participant checked. That is, when a participant checked "yes" for an emotion, the following questions popped up: "For every feeling you checked above, please rate how intense it was using the following scale" $(1=$ not at all intense, 7 = extremely intense) and "For every feeling you checked above, please rate how frequently you experienced it this week using the following scale" ( $1=$ very rarely, $7=$ all the time $)$. Cronbach's $\alpha$ for this scale ranged from 0.89 to 0.91 over the 8 weeks. Cronbach's $\alpha$ for just the positive emotions ranged from 0.91 to 0.93 over the 8 weeks.

Passionate Love Scale. We assessed passionate love using 
Hatfield and Sprecher's (1986) Passionate Love Scale. This is a 14-item measure using a 9-point Likert-type scale $(1=$ not at all true, $9=$ definitely true) to assess the amount of passion the participant feels toward his or her current relationship partner. Items include "I would feel despair if __ left me" and "Sometimes I feel I can't control my thoughts; they are obsessively on . . Reliability estimates were high (Cronbach's $\alpha=0.92$ to 0.97 ) for the 8 weeks.

\section{Overview of Analyses}

Because the design was longitudinal, we used multilevel modeling to analyze the data (with SAS proc mixed). Multilevel modeling allowed us to simultaneously estimate betweenperson and within-person changes in well-being over time. Thus, we were able to examine how individuals change over time (within person), and how individuals differ in their initial well-being and their changes in well-being.

We ran Ordinary Least Squares (OLS) regression to determine the average shape of individuals' trajectories, and the R2 estimates for a cubic model were higher than those of a linear or a quadratic model. Thus, our baseline multilevel model was cubic:

$$
\begin{aligned}
Y_{i j} & =\gamma_{00}+\gamma_{10} \text { Week }_{i j}+\gamma_{20} \text { Week }_{i j}^{2}+\gamma_{30} \text { Week }_{i j}^{3} \\
& +\left[\zeta_{0 i}+\zeta_{1 i} \text { Week }_{i j}+\zeta_{2 i} \text {Week }_{i j}^{2}+\zeta_{3 i} \text { Week }_{i j}^{3}+\varepsilon_{i j}\right]
\end{aligned}
$$

Our dependent variable $\left(Y_{i j}\right)$ was the number of positive emotions participants experienced that week. The intercept term $\left(\gamma_{00}\right)$ represents the average number of positive emotions reported during Week 2. Week was centered on Week 2 because our model is cubic, and thus centering on Week 1 would make it more difficult to interpret the nonlinear parameters. The $\gamma_{10}$ parameter, associated with the Week predictor, is the average rate of change in the number of positive emotions reported. The $\gamma_{20}$ parameter, associated with the Week ${ }^{2}$ predictor, is the curvature parameter, which represents the rate at which the slope changes. The $\gamma_{30}$ parameter is associated with the Week $^{3}$ predictor and represents the rate at which the curvature changes. The portion of the model in brackets represents the error terms.

\section{Results}

Because our intended well-being measure (i.e., "current well-being") had low reliability for the relationship group, we opted to use as our key measure of well-being the number of positive emotions that participants reported. Overall, as expected, a significant decline in positive affect over time was observed for both the relationship and control groups (see Figure 1, top). Although the groups did not significantly differ in rate of decline (see Table 1, far right column), they did differ in the intercept (second to last column). A comparison with the baseline model suggested that adding "group" as a predictor marginally improved fit, $\chi^{2}(1)=3.2, p=0.07$. In addition, a model with the interaction term (Group X Week) to predict the slope did not show a significantly better fit than a model with no interaction term, $\chi^{2}(1)=1.7, p=0.19$. Thus, the relationship group had significantly higher positive affect at Week 2 (the intercept) than the control group, but the two groups did not significantly differ in slope. Because we were interested in the predictors of positive affect for those in romantic relationships, all further analyses examined just the relationship group.
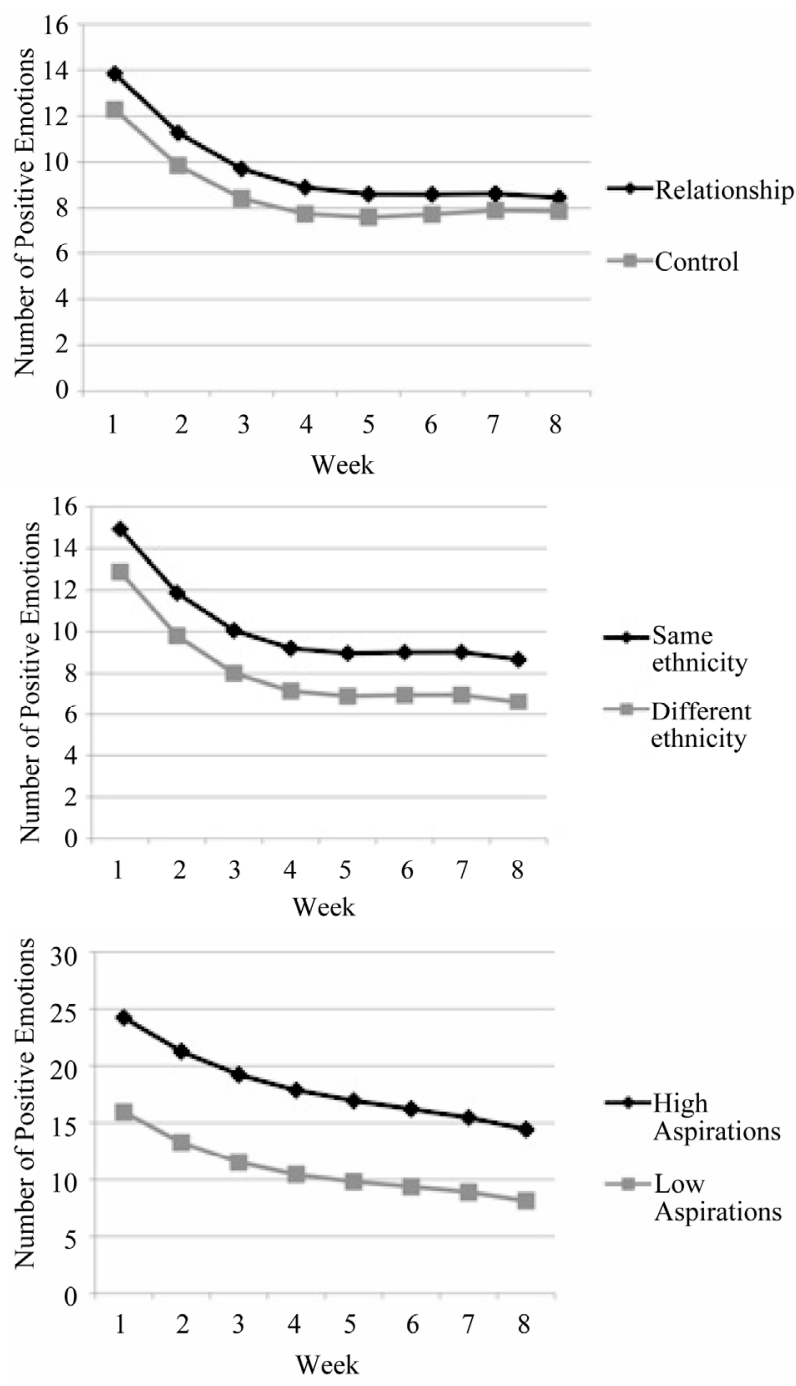

Figure 1.

Group membership (relationship vs. control) predicting number of positive emotions over time (top). Ethnicity composition of relationship predicting number of positive emotions over time (left). Aspirations predicting number of positive emotions over time (right).

\section{Demographics}

We tested whether the amount of time a person had been dating their partner influenced their positive affect or the change in positive affect over time. Contrary to our hypotheses, the amount of time a person had been dating was not a significant predictor of positive affect at Week 2 (the intercept) or the change in positive affect over time (see Table 2, left). The goodness of fit of these models did not significantly differ from the baseline model, $\chi^{2}<1, p>.05$. We did retain the model with dating duration as a predictor as a comparison model for subsequent analyses, because we wanted to be able to interact the dating duration variable with time-varying predictors. Thus, our comparison model for all subsequent analyses was as follows:

$$
\begin{aligned}
Y_{i j} & =\gamma_{00}+\gamma_{10} \text { Week }_{i j}+\gamma_{20} \text { Week }_{i j}^{2}+\gamma_{30} \text { Week }_{i j}^{3}+\gamma_{01} \text { TimeDating } \\
& +\left[\zeta_{0 i}+\zeta_{1 i} \text { Week }_{i j}+\zeta_{2 i} \text { Week }_{i j}^{2}+\zeta_{3 i} \text { Week }_{i j}^{3}+\varepsilon_{i j}\right]
\end{aligned}
$$




\section{K. JACOBS BAO}

Table 1.

Group predicting positive affect—all participants.

\begin{tabular}{|c|c|c|c|c|c|}
\hline & Effect & Param & Baseline & Group & Group $\times$ Week \\
\hline \multirow{6}{*}{ Fixed Effects } & Intercept & $\gamma_{00}$ & $10.47^{* * *}$ & $9.93^{* * *}$ & $9.85^{* * *}$ \\
\hline & Week & $\gamma_{10}$ & $-1.96^{* * *}$ & $-1.96^{* * *}$ & $-1.89^{* * *}$ \\
\hline & Week ${ }^{2}$ & $\gamma_{20}$ & $0.50^{* * *}$ & $0.50^{* * *}$ & $0.50^{* * *}$ \\
\hline & Week ${ }^{3}$ & $\gamma_{30}$ & $-0.04^{* * *}$ & $-0.04^{* * *}$ & $-0.04^{* * *}$ \\
\hline & Group & $\gamma_{01}$ & - & 1.22 & $1.42^{*}$ \\
\hline & $\mathrm{Grp} \times \mathrm{Wk}$ & $\gamma_{02}$ & - & - & -0.14 \\
\hline \multirow{5}{*}{ Random Effects } & Level 1 & $\sigma_{\varepsilon}^{2}$ & $12.95^{* * *}$ & $12.96^{* * *}$ & $12.96^{* * *}$ \\
\hline & \multirow{4}{*}{ Level 2} & $\sigma_{0}^{2}$ & $30.01^{* * *}$ & $29.63^{* * *}$ & $29.65^{* * *}$ \\
\hline & & $\sigma_{1}^{2}$ & $2.14^{* * *}$ & $2.14^{* * *}$ & $2.09^{* * *}$ \\
\hline & & $\sigma_{2}^{2}$ & 0.24 & 0.24 & 0.24 \\
\hline & & $\sigma_{3}^{2}$ & 0.002 & 0.002 & 0.002 \\
\hline \multirow{3}{*}{ Good- ness of Fit } & Deviance & & 10904.5 & 10901.3 & 10899.6 \\
\hline & AIC & & 10934.5 & 10933.3 & 10933.6 \\
\hline & $\mathrm{BIC}$ & & 10988.7 & 10991.1 & 10995.0 \\
\hline
\end{tabular}

Note: ${ }^{*} p<0.05 ;{ }^{* *} p<0.01 ;{ }^{* * *} p<0.001$.

Table 2.

Time dating, sex composition, and ethnicity composition predicting positive affect-relationship group only.

\begin{tabular}{|c|c|c|c|c|c|c|c|c|c|}
\hline & \multirow[b]{2}{*}{ Effect } & \multirow[b]{2}{*}{ Param } & \multicolumn{3}{|c|}{ Time Dating } & \multicolumn{2}{|c|}{ Sex Composition } & \multicolumn{2}{|c|}{ Ethnicity Composition } \\
\hline & & & Baseline & Time Dating & $\begin{array}{l}\text { Time Dating } \\
\text { Week }\end{array}$ & Sex Comp. & Sex Comp $\times$ Week & $\begin{array}{l}\text { Ethnicity } \\
\text { Comp }\end{array}$ & $\begin{array}{l}\text { Ethnicity Comp } \times \\
\text { Week }\end{array}$ \\
\hline \multirow{7}{*}{$\begin{array}{l}\text { Fixed } \\
\text { Effects }\end{array}$} & Intercept & $\gamma_{00}$ & $11.14^{* * *}$ & $10.66^{* * *}$ & $10.63^{* * *}$ & $10.35^{* * *}$ & $10.60^{* * *}$ & $11.86^{* * *}$ & $11.84^{* * *}$ \\
\hline & Week & $\gamma_{10}$ & $-2.37^{* * *}$ & $-2.37^{* * *}$ & $-2.33^{* * *}$ & $-2.37^{* * *}$ & $-2.64^{* * *}$ & $-2.38^{* * *}$ & $-2.35^{* * *}$ \\
\hline & Week ${ }^{2}$ & $\gamma_{20}$ & $0.63^{* * *}$ & $0.63^{* * *}$ & $0.63^{* * *}$ & $0.63^{* * *}$ & $0.63^{* * *}$ & $0.63^{* * *}$ & $0.63^{* * *}$ \\
\hline & Week $^{3}$ & $\gamma_{30}$ & $-0.05^{* * *}$ & $-0.05^{* * *}$ & $-0.05^{* * *}$ & $-0.05^{* * *}$ & $-0.05^{* * *}$ & $-0.05^{* * *}$ & $-0.05^{* * *}$ \\
\hline & Time Dating & $\gamma_{01}$ & - & 0.0008 & 0.0008 & 0.0008 & 0.0008 & 0.001 & 0.001 \\
\hline & $\begin{array}{c}\text { Time Dating } \\
\times \text { Week }\end{array}$ & $\gamma_{02}$ & - & - & $\begin{array}{c}-0.00006 \\
\text { (Time Dating } \times \\
\text { Week) }\end{array}$ & $\begin{array}{c}0.38 \\
\text { (Sex Comp) }\end{array}$ & $\begin{array}{c}0.07 \\
\text { (Sex Comp) }\end{array}$ & $\begin{array}{c}-2.05^{*} \\
\text { (Eth Comp) }\end{array}$ & $\begin{array}{c}-2.02^{*} \\
\text { (Eth Comp) }\end{array}$ \\
\hline & & $\gamma_{03}$ & - & - & - & - & $\begin{array}{c}0.34 \\
\text { (Sex Comp } \times \\
\text { Week) }\end{array}$ & - & $\begin{array}{c}-0.04 \\
(\text { Eth Comp } \times \text { Week })\end{array}$ \\
\hline \multirow{5}{*}{$\begin{array}{l}\text { andom } \\
\text { Effects }\end{array}$} & Level 1 & $\sigma_{\varepsilon}^{2}$ & $14.55^{* * *}$ & $14.56^{* * *}$ & $14.56^{* * *}$ & $14.56^{* * *}$ & $14.57^{* * * *}$ & $14.52^{* * *}$ & $14.52^{* * *}$ \\
\hline & & $\sigma_{0}^{2}$ & $23.32^{* * *}$ & $23.06^{* * *}$ & $23.06^{* * *}$ & $23.16^{* * *}$ & $23.13^{* * *}$ & $22.36^{* *}$ & $22.35^{* * *}$ \\
\hline & & $\sigma_{1}^{2}$ & $2.80^{* *}$ & $2.81^{* *}$ & $2.82^{* *}$ & $2.81^{* *}$ & $2.81^{* *}$ & $2.87^{* *}$ & $2.88^{*}$ \\
\hline & Level 2 & $\sigma_{2}^{2}$ & $0.59^{*}$ & $0.59^{*}$ & $0.59^{*}$ & $0.59^{*}$ & $0.59^{*}$ & $0.60^{*}$ & $0.60^{*}$ \\
\hline & & $\sigma_{3}^{2}$ & 0.006 & 0.006 & 0.006 & 0.006 & 0.006 & 0.007 & 0.007 \\
\hline \multirow{3}{*}{$\begin{array}{l}\text { Goodness of } \\
\text { Fit }\end{array}$} & Deviance & & 5013.5 & 5012.8 & 5012.6 & 5012.6 & 5009.4 & 4967 & 4966.9 \\
\hline & AIC & & 5043.5 & 5044.8 & 5046.6 & 5046.6 & 5045.4 & 5001 & 5002.9 \\
\hline & BIC & & 5085.3 & 5089.4 & 5094 & 5094 & 5095.6 & 5048.2 & 5052.9 \\
\hline
\end{tabular}

Note: ${ }^{*} p<0.05 ;{ }^{* *} p<0.01 ;{ }^{* * *} p<0.001$. 


\section{K. JACOBS BAO}

Contrary to our predictions, whether a participant was in a same-sex or opposite-sex relationship did not predict change in positive affect over time. The goodness of fit test for this model was not significantly different from the comparison model, $\chi^{2}$ (2) $=3.4, p=0.18$. The gender composition of the couple did not significantly predict the intercept either, $\chi^{2}(1)=0.2, p=$ 0.65 (see Table 2, middle). Thus, participants in same-sex relationships did not differ in positive affect at Week 2 and did not decline in positive affect more slowly than those in oppositesex relationships.

We hypothesized that those in different-ethnicity relationships would have a shallower decline in positive affect over time, but this hypothesis was not supported (see Table 2, right). No significant difference emerged in goodness of fit between a model with the Ethnicity Composition X Week interaction term and our comparison model, $\chi^{2}(2)=0.1, p=0.75$. However, the intercept was a significant predictor of positive affect, $\chi^{2}(1)=$ 45.8, $p<0.0001$, indicating that those who were in different-ethnicity relationships had lower positive affect at Week 2 than those who were in same-ethnicity relationships (see Figure 1 , middle).

\section{Aspirations}

Aspirations were a significant predictor of the intercept for positive affect, but not the slope. Aspirations significantly pre- dicted positive affect at Week 2 (see Table 3, left). The goodness of fit index for this model was significantly different from that of the comparison model, $\chi^{2}(6)=104.7, p<0.0001$. However, the relationship between aspirations and positive affect was in the opposite direction than we predicted. Higher aspirations were predictive of higher positive affect, rather than lower positive affect (see Figure 1, bottom). Contrary to our hypothesis, aspirations did not predict change in positive affect over time, $\left.\chi^{2}(1)=0.9, p=0.34\right)$.

\section{Passionate Love}

Supporting our hypothesis, passionate love was a significant predictor of positive affect. Higher passionate love was predictive of higher positive affect at Week 2 (see Table 3, right). The goodness of fit index of this model was significantly different from that of the comparison model, $\chi^{2}(6)=48.6, p<$ 0.0001 . However, passionate love was not a significant predictor of the change in positive affect over time. The goodness of fit for a model predicting the slope was not significantly different from the comparison model, $\chi^{2}(1)=1.3, p=0.25$.

We also tested whether a significant interaction existed between dating duration and passionate love scores. We did not find support for this model, $\chi^{2}(1)=2.1, p=0.15$; see Table 3 , right). Thus, the interaction between dating duration and passionate love scores did not significantly predict positive affect

Table 3.

Aspirations and passionate love predicting positive affect—relationship group only.

\begin{tabular}{|c|c|c|c|c|c|c|c|c|c|}
\hline & \multirow[b]{2}{*}{ Effect } & \multirow[b]{2}{*}{ Param } & \multicolumn{3}{|c|}{ Aspirations } & \multicolumn{4}{|c|}{ Passionate Love } \\
\hline & & & $\begin{array}{l}\text { Comparison } \\
\text { Model }\end{array}$ & Asp & $\begin{array}{l}\text { Asp } \times \\
\text { Week }\end{array}$ & $\begin{array}{l}\text { Comparison } \\
\text { Model }\end{array}$ & Pass Love & $\begin{array}{l}\text { Pass Love } \times \\
\text { Week }\end{array}$ & $\begin{array}{l}\text { Pass. Love } \times \\
\text { Time Dating }\end{array}$ \\
\hline \multirow{8}{*}{$\begin{array}{l}\text { Fixed } \\
\text { Effects }\end{array}$} & Intercept & $\gamma_{00}$ & $10.61^{* * *}$ & $11.14^{* * *}$ & $11.17^{* * *}$ & $10.61^{* * *}$ & $10.62^{* * *}$ & $10.63^{* * *}$ & $10.68^{* * *}$ \\
\hline & Week & $\gamma_{10}$ & $-2.40^{* * *}$ & $-2.12^{* * *}$ & $-2.11^{* * *}$ & $-2.40^{* * *}$ & $-2.27^{* * *}$ & $-2.25^{* * *}$ & $-2.27^{* * *}$ \\
\hline & Week $^{2}$ & $\gamma_{20}$ & $0.65^{* * *}$ & $0.47^{* * *}$ & $0.46^{* * *}$ & $0.65^{* * *}$ & $0.59^{* * *}$ & $0.59^{* * *}$ & $0.60^{* * *}$ \\
\hline & Week $^{3}$ & $\gamma_{30}$ & $-0.06^{* * *}$ & $-0.04^{* * *}$ & $-0.04^{* * *}$ & $-0.06^{* * *}$ & $-0.05^{* * *}$ & $-0.05^{* * *}$ & $-0.05^{* * *}$ \\
\hline & $\begin{array}{l}\text { Time } \\
\text { Dating }\end{array}$ & $\gamma_{01}$ & 0.0004 & 0.0004 & 0.0003 & 0.0004 & 0.0009 & 0.0009 & 0.0009 \\
\hline & & $\gamma_{02}$ & - & $\begin{array}{l}0.02^{* * *} \\
\text { (Asp) }\end{array}$ & $\begin{array}{l}0.02^{* * *} \\
\text { (Asp) }\end{array}$ & - & $\begin{array}{c}1.10^{* * *} \\
\text { (Pass Love) }\end{array}$ & $\begin{array}{c}1.23^{* * *} \\
\text { (Pass Love) }\end{array}$ & $\begin{array}{c}1.46^{* * *} \\
\text { (Pass Love) }\end{array}$ \\
\hline & & $\gamma_{03}{ }^{\mathrm{a}}$ & - & - & $\begin{array}{l}-0.0007 \\
(\text { Asp } \times \\
\text { Week) }\end{array}$ & - & - & $\begin{array}{c}-0.06 \\
\text { (Pass Love } \times \\
\text { Week) }\end{array}$ & - \\
\hline & & $\gamma_{03}{ }^{\mathrm{a}}$ & - & - & - & - & - & - & $\begin{array}{c}-0.0006^{*}(\text { Pass } \\
\text { Love } \times \text { Time } \\
\text { Dating })\end{array}$ \\
\hline \multirow{6}{*}{$\begin{array}{l}\text { Random } \\
\text { Effects }\end{array}$} & Level 1 & $\sigma_{\mathrm{\varepsilon}}^{2}$ & $14.51^{* * *}$ & $12.81^{* * *}$ & $12.82^{* * *}$ & $14.51^{* * *}$ & $13.81^{* * *}$ & $13.81^{* * *}$ & $13.92^{* * *}$ \\
\hline & & $\sigma_{0}^{2}$ & $22.67^{* * *}$ & $21.79^{* *}$ & $21.93^{* * *}$ & $22.67^{* * *}$ & $22.82^{* * *}$ & $23.20^{* * *}$ & $22.27^{* * *}$ \\
\hline & & $\sigma_{1}^{2}$ & $2.90^{* *}$ & $1.60^{*}$ & $1.58^{*}$ & $2.90^{* *}$ & $2.80^{* *}$ & $2.75^{* *}$ & $2.97^{* *}$ \\
\hline & Level 2 & $\sigma_{2}^{2}$ & $0.63^{*}$ & 0.11 & 0.11 & $0.63^{*}$ & 0.45 & 0.46 & 0.45 \\
\hline & & $\sigma_{3}^{2}$ & 0.007 & 0 & 0 & 0.007 & 0.004 & 0.004 & 0.003 \\
\hline & & $\sigma_{4}^{2}$ & - & $0.0002^{* *}$ & $0.0002^{* *}$ & - & 0.43 & 0.43 & 0.31 \\
\hline \multirow{3}{*}{$\begin{array}{c}\text { Goodness } \\
\text { of Fit }\end{array}$} & Deviance & & 4977.1 & 4872.4 & 4871.5 & 4977.1 & 4928.5 & 4927.2 & 4926.4 \\
\hline & AIC & & 5009.1 & 4914.4 & 4915.5 & 5009.1 & 4972.5 & 4973.2 & 4972.4 \\
\hline & BIC & & 5053.7 & 4972.9 & 4976.8 & 5053.7 & 5033.8 & 5037.3 & 5036.5 \\
\hline
\end{tabular}

Note: ${ }^{*} p<0.05 ;{ }^{* *} p<0.01 ;{ }^{* * *} p<0.001$. ${ }^{\mathrm{a}}$ The two passionate love interaction terms were not included in the same model. 
at the intercept (Week 2).

\section{Discussion}

Our findings showed that all our participants-both those who were involved in relationships and those who were notreported experiencing fewer positive emotions over the 8 weeks of the study. None of the variables we measured significantly predicted this change in positive affect, however, but the ethnicity composition of the relationship (i.e., different-ethnicity vs same-ethnicity), self-reported aspirations, and passionate love significantly predicted the dating participants' initial positive affect.

As hypothesized, those in the relationship group reported more positive emotions than those in the control group, although this difference was only marginally significant. Many studies have found that married people are happier than unmarried people (see Lyubomirsky, King et al., 2005, for a review). Although fewer studies have examined non-married couples, research suggests that people in committed and dating relationships are happier than those who are single (e.g., Dush \& Amato, 2005).

As in previous studies, our undergraduate participants declined in well-being over the course of the study, on average (Lyubomirsky, Sheldon et al., 2005). This may be because students typically experience increased stress and pressing deadlines as the academic quarter progresses, and thus experi- ence a decline in happiness. No difference emerged, however, in the rate of well-being decline between the relationship and control groups.

Surprisingly, the amount of time participants had been in a romantic relationship was not a significant predictor of their positive affect at Week 2 or the rate at which their positive affect declined. This was contrary to our hypotheses, but may be explained by the fact that we only followed our participants for 2 months and that, when they began our study, many of them had already been dating for a long period of time $(M=$ 633 days, $M d n=425$ days). It is likely that 8 weeks is not long enough to capture meaningful changes in well-being, especially in long-dating participants who may have already adapted to their relationships when they entered our study.

Participants in same-sex relationships did not differ from participants in opposite-sex relationships in initial positive affect or in change in positive affect over time. Although this finding countered our hypotheses, it was not too surprising. Those in same-sex relationships may have experienced few obstacles in the relatively liberal college environment that served as the setting for our study. Thus, our participants who were involved in same-sex relationships may not have experienced much disapproval or censure.

Participants in different-ethnicity relationships had significantly lower positive affect at Week 2 than those in sameethnicity relationships, but there was no group difference in the rate of decline of positive affect. A possible explanation is that those in different-ethnicity relationships experience frowns or disapproval from their family members or others, which could lower their positive affect, especially if they live at home. This argument is bolstered by the fact that a higher than average percentage of students from which the college where our participants were recruited reside at home. Finally, we hypothesized that outside disapproval would increase positive affect, as the participants may respond to adversity by becoming closer to their partner (i.e., an "us against the world" mindset), but we did not find evidence of such a process.

We also found that higher aspirations predicted higher positive affect but did not predict a change in positive affect over time. Although this is the reverse of what we hypothesized, similar results have been found with the aspirations measure used in the current study (Boehm, 2010). Our speculation is that our measure of aspirations did not actually tap aspirations but, instead, ended up serving as an indicator of well-being. For example, we asked our control participants, "How do you expect to feel this week?" and our relationship participants, "How do you expect to feel this week about your relationship partner?" Participants' responses may have been strongly influenced by their current moods, thus rendering the measure more diagnostic of their current well-being than their aspirations for the next week. In the future, researchers should aim to develop new measures that show an ability to discriminate between aspirations and well-being. For instance, it may be that people's general aspirations are too closely linked with well-being, but more specific aspirations (e.g., how many times a person expects to see her partner next week) may not be. Thus, a measure that taps more specific aspirations, or even aspirations for specific life domains (e.g., Kasser \& Ryan, 1993), may be predicttive of changes in well-being over time.

Finally, passionate love scores were predictive of participants' positive affect at Week 2 , but not of the change in positive affect over time. Thus, higher passionate love scores predicted higher positive affect, which is consistent with previous research (Kim \& Hatfield, 2004). The interaction between passionate love scores and relationship duration was not a significant predictor of positive affect, however. Thus, time dating did not moderate the relationship between passionate love and positive affect, suggesting that differences in well-being of those who reported higher or lower passionate love did not change depending on the length of the relationship.

\section{Limitations}

The current study had several limitations. First, we did not measure participants' well-being before they entered into a relationship, so we could not study the full course of the adaptation process. Well-being needs to be assessed prior to participants starting a relationship, so that shifts in well-being over time could be compared to baseline well-being (i.e., how happy the participants were before receiving the hypothesized "boost" from beginning a new relationship). This way, it is possible to determine when adaptation begins and when participants have returned to their baseline well-being level. Ideally, future studies would recruit participants who are actively seeking a relationship, such as those on a dating web site, and measure their well-being before and after starting a relationship. Such a design would allow us to model the entire adaptation process from beginning to end, as similar studies have done with married couples (e.g., Lucas et al., 2003).

Another limitation is that our study only followed the par- ticipants for 8 weeks, which is a short period of time compared to other studies that have examined changes in relationship satisfaction and well-being (e.g., Lucas et al., 2003). Indeed, many relationship and marriage studies follow participants for years, and thus are able to observe significant changes in satisfaction over time. We may have seen more meaningful changes in well-being - and been able to capture the role of key mod- 
erators and mediators in the adaptation process - if we had followed our participants for longer than 8 weeks. Furthermore, the nonlinearity of the data decreased the power, decreasing the chances of finding significant predictors of changes in positive emotions over time.

\section{Future Research}

Future research should strive to recruit a broader samplebeyond merely college students - as the pattern of results may differ for older participants. Young adults, many of whom may be in their first serious relationships, may be less likely to adapt rapidly to such novel experiences. They may be more likely to savor and appreciate the experiences because they are undergoing them for the first time. Young adults also may feel less rushed in their relationships (e.g., to get married or start a family), and thus may have more time to relish their relationship experiences. Also, by assessing participants on many occasions, including weeks, months, or years before they start a romance, we may obtain a better understanding of the processes underlying adaptation to intimate relationships. Such a long period of assessment would allow us to capture not only those who adapt relatively quickly (e.g., days or weeks), but also those who may take years to adapt to their relationships. In addition, we would be able to observe different trajectories of well-being over time and possibly connect those changes in well-being with different life events (e.g., getting engaged, having a child, etc.) or with individual difference variables (e.g., sex or ethnicity composition of the relationship or personality).

Furthermore, it is important to use a sample of participants who are in dating, rather than married, relationships, because much of the adaptation process occurs before one even starts to think about getting married. The first few months of a relationship may entail the biggest changes in well-being, and thus it is important to capture those months using a dating population. We may even find that a relationship is characterized by multiple adaptation periods. Lucas and colleagues (2003) have found evidence of adaptation to marriage, but adaptation may also occur to the beginning of the premarital relationship. It would be interesting to compare a person's baseline well-being to her well-being after adapting to a new relationship and, later, after adapting to marriage to her relationship partner. It is possible that people adapt completely to marriage, but they do not adapt completely to the premarital relationship. These and other questions about well-being and hedonic adaptation remain. Learning the answers to these questions will aid in understanding how people can thwart adaptation to relationships, which will promote greater relationship satisfaction, higher well-being, and may even help to lengthen relationships.

\section{REFERENCES}

Aron, A., Norman, C. C., Aron, E. N., McKenna, C., \& Heyman, R. E. (2000). Couples' shared participation in novel and arousing activities and experienced relationship quality. Journal of Personality and Social Psychology, 78, 273-284. doi:10.1037/0022-3514.78.2.273

Boehm, J. K. (2010). Getting used to the good things in life: Hedonic adaptation to positive life events. Dissertation Abstracts International, 70, 5229B.

Boswell, W. R., Boudreau, J. W., \& Tichy, J. (2005). The relationship between employee job change and job satisfaction: The honeymoonhangover effect. Journal of Applied Psychology, 90, 882-892. doi:10.1037/0021-9010.90.5.882
Diener, E., Suh, E. M., Lucas, R. E., \& Smith, H. L. (1999). Subjective well-being: Three decades of progress. Psychological Bulletin, 125, 276-302. doi:10.1037/0033-2909.125.2.276

Donovan, C., Heaphy, B., \& Weeks, J. (1999). Citizenship and same sex relationships. Journal of Social Policy, 28, 689-709. doi:10.1017/S0047279499005747

Dush, C. M. K., \& Amato, P. R. (2005). Consequences of relationship status and quality for subjective well-being. Journal of Social and Personal Relationships, 22, 607-627. doi: $10.1177 / 0265407505056438$

Frederick, S., \& Loewenstein, G. (1999). Hedonic adaptation. In D. Kahneman, E. Diener, \& N.Schwarz (Eds.), Well-being: The foundations of hedonic psychology (pp. 302-329). New York: Russell Sage Foundation.

Hatfield, E., \& Sprecher, S. (1986). Measuring passionate love in intimate relations. Journal of Adolescence, 9, 383-410.

Karney, B. R., \& Bradbury, T. N. (1995) The longitudinal course of marital quality and stability: A review of theory, method, and research. Psychological Bulletin, 118, 3-34.

doi:10.1037/0033-2909.118.1.3

Kasser, T., \& Ryan, R. M. (1993). A dark side of the American dream: Correlates of financial success as a central life aspiration. Journal of Personality and Social Psychology, 65, 410-422. doi:10.1037/0022-3514.65.2.410

Kim, J., \& Hatfield, E. (2004). Love types and subjective well being. Social Behavior and Personality: An International Journal, 32, 173182. doi:10.2224/sbp.2004.32.2.173

Kurdek, L. (1999). The nature and predictors of the trajectory of change in marital quality for husbands and wives over the first 10 years of marriage. Developmental Psychology, 35, 1283-1296. doi: $10.1037 / 0012-1649.35 .5 .1283$

Kurdek, L. A. (2002). Predicting the timing of separation and marital satisfaction: An eight-year prospective longitudinal study. Journal of Marriage and the Family, 64, 163-179. doi:10.1111/j.1741-3737.2002.00163.x

Kurdek, L. A. (2004). Are gay and lesbian cohabiting couples really different from heterosexual married couples? Journal of Marriage and Family, 66, 880-900. doi:10.1111/j.0022-2445.2004.00060.x

Layard, R. (2005). Happiness: Lessons from a new science. New York: Penguin Press.

Lucas, R. E. (2005). Time does not heal all wounds: A longitudinal study of reaction and adaptation to divorce. Psychological Science, 16, 945-950. doi:10.1111/j.1467-9280.2005.01642.x

Lucas, R. E. (2007). Long-term disability is associated with lasting changes in subjective well being: Evidence from two nationally representative longitudinal studies. Journal of Personality and Social Psychology, 92, 717-730. doi:10.1037/0022-3514.92.4.717

Lucas, R. E. \& Clark, A. E. (2006). Do people really adapt to marriage? Journal of Happiness Studies, 7, 405-426. doi:10.1007/s10902-006-9001-X

Lucas, R. E., Clark, A. E., Georgellis, Y., \& Diener, E. (2003). Reexamining adaptation and the setpoint model of happiness: Reactions to changes in marital status. Journal of Personality and Social Psychology, 84, 527-539. doi:10.1037/0022-3514.84.3.527

Lucas, R. E., Clark, A. E., Georgellis, Y., \& Diener, E. (2004). Unemployment alters the set point for life satisfaction. Psychological Science, 15, 8-13. doi:10.1111/j.0963-7214.2004.01501002.x

Lyubomirsky, S. (2011). Hedonic adaptation to positive and negative experiences (pp. 200-224). In S. Folkman (Ed.), Oxford handbook of stress, health, and coping. New York: Oxford University Press.

Lyubomirsky, S., King, L., \& Diener, E. (2005). The benefits of frequent positive affect: Does happiness lead to success? Psychological Bulletin, 131, 803-855. doi:10.1037/0033-2909.131.6.803

Murstein, B., Merigihi, J. R., \& Malloy, T. E. (1989). Physical attractiveness and exchange theory in interracial dating. The Journal of Social Psychology, 129, 325-334. doi: $10.1080 / 00224545.1989 .9712049$

Rusbult, C. E. (1983). A longitudinal test of the investment model: The development (and deterioration) of satisfaction and commitment in heterosexual involvements. Journal of Personality and Social Psy- 


\section{K. JACOBS BAO}

chology, 1, 101-117. doi:10.1037/0022-3514.45.1.101

Sheldon, K. M., \& Lyubomirsky, S. (2012). The challenge of staying happier: Testing the Hedonic Adaptation Prevention (HAP) model. Personality and Social Psychology Bulletin, 38, 670-680. doi: $10.1177 / 0146167212436400$

Tsapelas, I., Aron, A., \& Orbuch, T. (2009). Marital boredom now predicts less satisfaction 9 years later. Psychological Science, 20, 1-3. doi:10.1111/j.1467-9280.2009.02332.x

Willi, J. (1997). The significant of romantic love for marriage. Family Process, 36, 171-182. doi:10.1111/j.1545-5300.1997.00171.x

Zuckerman, M., \& Lubin, B. (1965). Normative data for the multiple affect adjective check list. Psychological Reports, 16, 438. doi:10.2466/pr0.1965.16.2.438 